\title{
From the recent lessons of the Malagasy foci towards a global understanding of the factors involved in plague reemergence
}

\author{
Jean-Marc DUPLANTIER ${ }^{\mathrm{a}, \mathrm{b} *}$, Jean-Bernard DUCHEMIN ${ }^{\mathrm{c}}$, \\ Suzanne CHANTEAU ${ }^{\mathrm{c}}$, Elisabeth CARNIEL ${ }^{\mathrm{d}}$ \\ a Programme RAMSE, IRD Madagascar, Madagascar \\ b Present address: Centre de Biologie et Gestion des Populations (CBGP, UMR 22), IRD, \\ BP 1386, Dakar CP 18524, Sénégal \\ ${ }^{\mathrm{c}}$ Institut Pasteur de Madagascar, Po Box 1274, Antananarivo, Madagascar \\ d Yersinia Research Unit, Institut Pasteur, 28 rue du Dr. Roux, 75724 Paris Cedex 15, France
}

(Received 1 May 2004; accepted 16 December 2004)

\begin{abstract}
Re-emergence of human cases of plague after decades of silence does not necessarily mean that plague foci are re-emerging. Most often, Yersinia pestis bacteria have been maintained and circulating at low levels in the rodent populations. It seems therefore more appropriate to speak in terms of expansion or regression phases for sylvatic rodent plague foci and to reserve the term reemergence for human cases. From the analysis of well-documented human plague cases in Madagascar, we underline the causes of re-emergence that can be generalized to most world foci, and can help define environments at risk where the threat of new emergence lurks. In all recent plague outbreaks, usually more than one risk factor was at the origin of the re-emergence. The reduction or discontinuance of surveillance and control, as well as poverty and insalubrity are the main factors in the re-emergence of human cases, allowing increased contacts with infected rodents and fleas. Environment changes (i.e. climatic changes, deforestation, urbanization) induce changes in flea and rodent populations by (i) extension of rodent habitats (for example by replacing forests by steppes or farmlands); (ii) modifications in population dynamics (possible outbreaks due to an increase of available food resources); but also, (iii) emergence of new vectors, reservoirs and new $Y$. pestis genotypes. Numerous and spontaneous genomic rearrangements occur at high frequencies in $Y$. pestis, which may confer selective advantages, enhancing the ability of $Y$. pestis to survive, to be transmitted to new hosts, and to colonize new environments. Therefore, any environmental change should be taken as a warning signal and active surveillance programs should be initiated.
\end{abstract}

plague / reemergence / Yersinia pestis / Madagascar / zoonosis

Table of contents

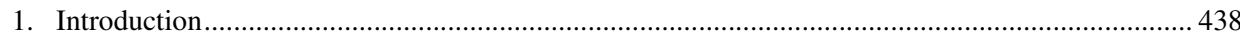

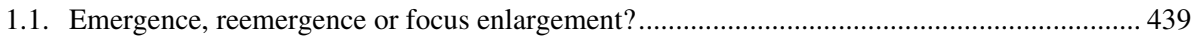

1.2. Current situation of human plague in the world................................................................. 439

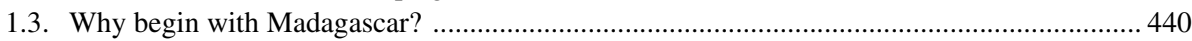

\footnotetext{
* Corresponding author: duplanti@ird.sn
} 


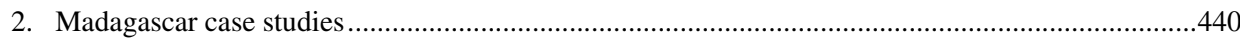

2.1. Mahajanga port: is a new reservoir involved? ....................................................................440

2.2. Antananarivo: Evolution of reservoir sensitivity, uncontrolled urbanization.........................441

2.3. Ikongo: deforestation and cultivation. Is the 800 -meter altitude limit still valid?...................442

2.4. Relic forests of the Highlands: new reservoirs, new vectors, new bacteria; appearance of a sylvatic cycle?

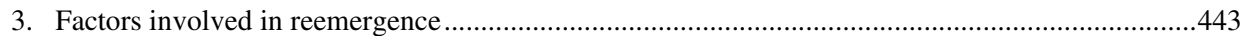

3.1. "Forgotten" ancient foci and discontinued surveillance .................................................443

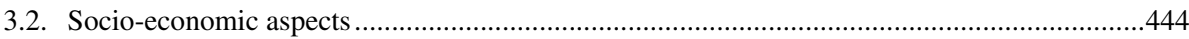

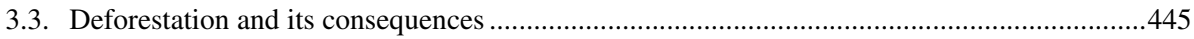

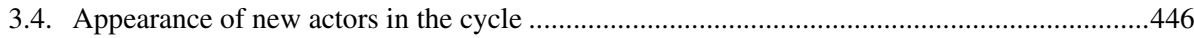

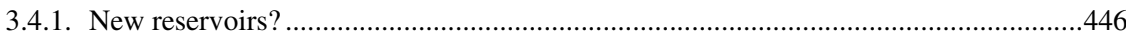

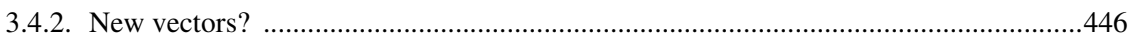

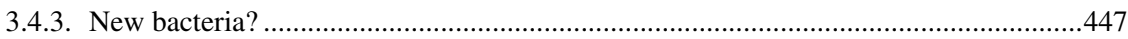

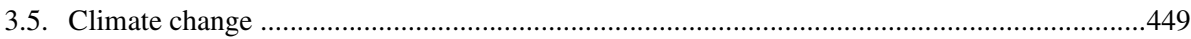

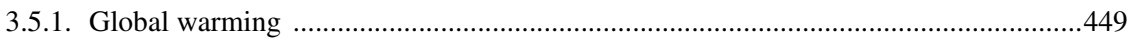

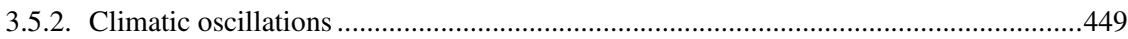

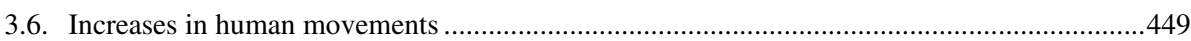

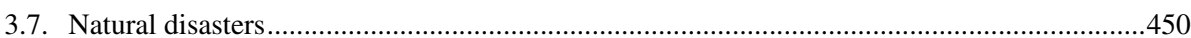

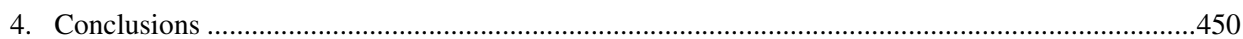

\section{INTRODUCTION}

"Plague is primarily a rodent disease that affects man only secondarily". This statement is generally made at the beginning of most reviews devoted to this disease, and the present paper will follow the example. Indeed, it is primordial to make a clear distinction between rodent and human plague if we want to understand how human cases reemerge in time and space and to determine whether we are talking about emergence or reemergence.

Thus, in China for example, ten natural foci are listed [31]: at the present time only, one involves human cases, five others have not been associated with any human cases for 25 to 50 years, and the remaining four appear purely enzootic. Natural rodent plague foci cover practically all the Western United States [58], while the number of human cases per year is there very low (4 to 10). Conversely, such foci appear insignificant, in Madagascar and Tanzania, however these countries report the highest number of human cases (several hundreds) to the World Health Organization (WHO) every year.
Plague is caused by the Yersin bacillus (Yersinia pestis) which is transmitted from one rodent to the next via the fleas of these rodents. Slightly over 200 species of rodents, but also certain lagomorphs (hares, rabbits) and insectivores (hedgehogs, shrews) have been found carrying this bacillus throughout the world [31]. Some eighty flea species in the world are regarded as vectors. Rodent plague is endemic over large areas throughout the world. Plague is not only found in warm regions, since it is also present in cold deserts (Central Asia) and in mountainous zones (in the USA in the Rocky Mountains, for example) where winters are harsh: in these zones, plague constantly circulates within rodent populations and their associated fleas. When a rodent population, sensitive to $Y$. pestis and living in contact with humans in villages or towns, is infected by the bacteria, this population is rapidly decimated, and then human cases appear. The plague flea vectors parasiting rodents are haematophagous insects: if their usual host disappears they have to feed on another mammal and on this occasion they can contaminate humans. 


\subsection{Emergence, reemergence or focus enlargement?}

Human plague has been known since ancient times and there have been three major pandemics, separated by centuries of respite [47].

The last plague pandemic began in China at the end of the 19th century and spread worldwide through all major ports within two decades, sparing only a few countries [47]. Therefore, all human foci that have appeared over the last decade are ancient foci; several had even disappeared for nearly 70 years (case of Mahajanga in Madagascar in 1991, of Oran in Algeria in 2003). If we disregard the particular and rare cases of imported plague (most recent example: New York, 2002, [8]), no human cases of plague are known to have appeared in previously unaffected areas to date. According to recent reviews [58, 62], over the last 50 years (1954-2004), two very clear peaks appear in the number of human cases reported to the $\mathrm{WHO}$, with the latter still ongoing. If we look at the evolution over time of the human cases of plague, it seems appropriate to speak of a reemerging disease.

However, when human cases reappear after decades of silence, that does not necessarily mean that the plague foci are reemerging. Could plague have continued circulating at low levels in rodent populations without contact and transmission to humans? On the contrary, had it completely disappeared from the particular area and then been reintroduced secondarily? Both scenarios are possible, although the former certainly occurs more frequently.

Indeed, most natural foci (rodents-fleasbacteria) survive during periods of silence in human populations: on the contrary, the case of Mahajanga in Madagascar is probably one of the few currently known foci where the bacillus may have been reintroduced. Natural foci, depending on weather conditions, habitat changes, and the population dynamics of reservoirs, can cover more or less extensive areas. Within these foci, the intensity of disease transmission depends mainly on the abundance of reservoirs and vectors. When this type of sylvatic focus grows in intensity or in size, human cases begin to appear inside or around it. From an ecological point of view, these long-term enzootic foci can be considered as "sources", whereas surrounding areas where plague appears only from time to time correspond to "sink areas" [48]. These foci are usually poorly or not monitored at all, and as a result the medical authorities only notice the return of the disease when human cases appear. Therefore, we find it more appropriate to speak in terms of expansion or regression phases for sylvatic rodent plague foci and to reserve the term reemergence for human cases.

\subsection{Current situation of human plague in the world}

Between 1987 and 2001, eleven African countries, five American countries and eight Asian countries reported human cases of plague to the WHO [62]. During this period, five countries declared cases every year: they are Madagascar, Tanzania, Vietnam, China and the USA, in a decreasing order. Seven other countries declared cases for 3 years out of 4 during this period: Myanmar (ex Burma), the Democratic Republic of Congo (ex Zaire), Namibia, Peru, Brazil, Mongolia and Kazakhstan. Finally, twelve countries reported cases only during specific years (1 to 6): Bolivia, Zimbabwe, Mozambique, Malawi, Uganda, Botswana, Zambia, Ecuador, Laos, Kenya, India and Indonesia. Since this review was prepared, one more country must be added: Algeria where a focus reappeared in Oran in June 2003 [63].

Such a list can help to distinguish between countries where human plague is permanently or almost permanently present, from countries where its presence is sporadic or cases are so few that they are likely to be missed by inadequate surveillance systems. Yet this distinction deserves another consideration: even within countries with 
endemic plague, some foci can reappear as in Madagascar. We can cite the following remarquable human outbreaks in recent years: - The port of Mahajanga, Madagascar, in 1991 [51], where plague had disappeared from the coastal areas of Madagascar for over 60 years; it is the recent reemerging focus with the highest number of human cases reported.

- Beed and Surat in 1994 in India, a country that had not reported any human cases of plague since 1967 [58]; this led to a massive human exodus from Surat.

- Mozambique in 1994 [2], after more than 15 years of silence. This led to the spread of the epidemic to the neighboring countries of Zimbabwe and Malawi.

- Zambia, end of 1996 [62], after a period of more than 30 years of silence.

- And finally the most recent outbreak was in Oran in June 2003 [63], although Algeria had been spared from human plague since 1955.

\subsection{Why begin with Madagascar?}

Our recent studies here have shown that this country presents all factors (socio-economical, failure of control strategies, appearance of new variants of the bacteria, new vectors, new reservoirs, ...) that have contributed to the reemergence of human plague in other parts of the world in various environments (urban, harbors, sylvatic, ....). From the analysis of precise and well-documented cases, we can underline the causes of reemergence that can be generalized to all foci, and can help define environments at risk where the threat of a new emergence is awaiting.

\section{MADAGASCAR CASE STUDIES}

Plague arrived in Madagascar during the third pandemic in 1898. It first affected the main harbor Tamatave, then the other harbors in subsequent years. During the 1920's it spread to the high plateau and disappeared from the coastal areas. Since then, the only foci remaining active are located in the center of the island, above $800 \mathrm{~m}$ of altitude. The only reservoir involved in disease transmission regardless of the type of focus (urban or rural) is the black rat Rattus rattus. Two vectors have been identified: Xenopsylla cheopis, the oriental rat flea, the most frequently involved throughout the world, but present in Madagascar only on rats living in houses; and an endemic flea, Synopsyllus fonquerniei, a parasite of rats living outdoors [6,7].

Plague reemerged at the end of the 1970's [9, 52], characterized by the following: a global increase in the number of human cases, the spreading of active foci, the reemergence of foci that were extinguished decades ago. This led us to question previous the characteristics of plague in Madagascar, described by Brygoo [6,7], as we will see in the following examples.

\subsection{Mahajanga port: is a new reservoir involved?}

After being silent over 60 years, plague reappeared in the Mahajanga port in 1991 and between 1995 and 1999 epidemics occurred every year $[3,4]$. This focus was able to persist despite the near absence of rats owing to a population of small mammals dominated to $90 \%$ by the Asian Shrew, Suncus murinus introduced into Madagascar probably in the middle of the 19th century [37]. It is certain that shrews played a major role in Mahajanga. During the years in which the cases of human plague were recorded (1991, then 1995-1999), they represented the major part of small mammal populations. They carried the flea $X$. cheopis and strains of $Y$. pestis were isolated from the spleen of tested shrews. The abundance of fleas on these shrews was at its maximum before the onset of the human plague season. Conversely, as soon as human plague ceased in 2000 the following was observed: (i) a decrease in shrew populations and an increase in rat populations; (ii) a decrease of the "cheopis" index for shrews; (iii) a disturbance in the annual cycles of abundance 
for shrews, fleas and anti-plague seroprevalences among small mammals. However it is difficult to determine whether they were simply hosts to plague-causing fleas or rather true reservoirs. Indeed, genetic analyses carried out at the Institut Pasteur in Paris (E. Carniel, personal communication) showed that while $Y$. pestis strains isolated from fleas, rats and humans had identical pulsotypes, those isolated from $S$. murinus $(n=2)$ had similar but different pulsotypes. This molecular strain analysis also suggests that the Mahajanga focus was recolonized by a strain that originated from the high plateaux of northern Madagascar. It is likely that when the inhabitants of these high plateaux traveled to the wholesale market, near the harbor, infected rats were transported along with foodstuffs, thus recolonizing the extinguished foci.

\subsection{Antananarivo: \\ Evolution of reservoir sensitivity, uncontrolled urbanization}

In the Malagasy capital, Antananarivo, human plague reappeared in 1979, after 28 years of silence. However, the daily rodent captures organized by the "Bureau Municipal d'Hygiène" showed that at that time, the sewer rat (Rattus norvegicus) represented $80 \%$ of captures versus only $20 \%$ for the black rat $(R \text {. rattus })^{1}$. Twenty years later, at the end of the 1990's, the sewer rat accounted for over $95 \%$ of all captures [49]. Since this species is not reputed to be very sensitive to plague, plague remained enzootic, although sporadic human cases occurred regularly. If we want to understand this phenomenon, we must compare the behavior of these two rats as well as the changes undergone in the urban landscape, and also the distribution of affected districts within the

\footnotetext{
${ }^{1}$ Rakotondravony A.D.S., Étude comparée de trois rongeurs des milieux malgaches : Rattus norvegicus Berkenhout (1769), Rattus rattus Linné (1757) et Eliurus sp., biologie et dynamique des populations, Ph.D. thesis, Université d'Antananarivo, 1992, 281 p.
}

town. The capital lies on hills surrounded by a floodplain. The oldest parts of the town are located higher up. With time, the traditional homes (low houses with thatched roofs) have been replaced by concrete or stone buildings and with the development of the sewage network, the black rat has been replaced by the sewer rat. Indeed, black rats are arboreal and thatched roofs provided them with a highly suitable habitat, while modernization of human housing has favored the more subterranean and even partly aquatic sewer rat, thus reducing the possibilities of contact between rats and humans. This concept is in agreement with the disappearance of human cases in the 1960's and 1970's.

At the beginning of the 1960's, the town of Antananarivo had only 300000 inhabitants, but now it has grown to far over $1.5 \mathrm{mil}-$ lion. The new townspeople have settled in poorer districts or at the periphery of the town in insalubrious lowlands, sometimes even on dikes located in the middle of rice fields. In these environments, as opposed to the ancient urban districts, the black rat is still present. Furthermore, natural floods or ricefield flooding regularly force black rats back up to the dikes and houses. Now the majority of human cases are concentrated precisely in these districts and around large markets. In the Isotry district (one of the largest markets), where transmission of $Y$. pestis among rodent populations is the highest (seroprevalence $>80 \%$ ), the situation appears paradoxical with very few reports of human cases and no observable epizootic. Actually, this enzootic focus functions with $R$. norvegicus and only a marginal proportion of $R$. rattus. Experimental infections by the subcutaneous route, have been carried out on "naive" animals (= born and raised in captivity), descending from individuals trapped in this district [49]. $R$. norvegicus showed exceptionally high resistance $\left(\mathrm{LD}_{50}=10^{3} \mathrm{cfu}\right)$ as compared to: (i) white laboratory rats (=R. norvegicus albino strain), $\mathrm{LD}_{50}<10 \mathrm{cfu}$; and (ii) $R$. norvegicus and $R$. rattus trapped in Malagasy plague free areas $\left(\mathrm{LD}_{50}<\right.$ $100 \mathrm{cfu})$. Unexpectedly, in the capital, 
$R$. rattus $\left(\mathrm{LD}_{50}=10^{5} \mathrm{cfu}\right)$ proved to be far more resistant to $Y$. pestis than $R$. norvegicus $\left(\mathrm{LD}_{50}=10^{3} \mathrm{cfu}\right)$. These very high levels of resistance explain the absence of an epizootic in the capital. Without high murine mortality and moreover, since the most abundant rat today ( $R$. norvegicus) is not in as close contact with human beings as $R$. rattus was, a human epidemic is unlikely. Only sporadic human cases (or within a family) are observed in the most insalubrious districts where the risk is higher due to more frequent contact between humans and rodents.

\subsection{Ikongo: deforestation and cultivation. Is the $800-\mathrm{m}$ altitude limit still valid?}

In October 1998, twenty-one cases of human plague were reported in the district of Ikongo, located south-east of the highlands, where no human cases had occurred for 33 years [41]. Human cases were reported in two villages: one is located at the bottom of the valley at $250 \mathrm{~m}$ of altitude, the other $(540 \mathrm{~m})$ lies along the eastern slopes leading to the island's central plateaus. Both localities are well below the 800-m altitude limit surrounding Madagascar's main plague focus [6]. In addition, they are separated from this focus by a large zone of forest. An epidemiological survey [41] showed that the human epidemic originated in the upper village. The first case occurred on October 14, however dead rats had already been seen in the village on September 28 and others had been found in the crops during the previous weeks. The two cases observed in the lower village were actually secondary cases resulting from a contamination during the funeral ceremonies of the first cases. The survey of the reservoirs and vectors [21] confirmed the secondary character of this focus: no positive serology was detected in the rodents captured in the lower village and no fleas were found on these rodents. The upper village had been abandoned in 1947 due to political events (rebellion against the colonial admin- istration) and its inhabitants had sought refuge lower in the valley. As of 1994, some inhabitants of the valley cleared and recultivated the site, they built houses and reoccupied the village on a permanent basis. During trapping operations after the epidemic [21], in this upper village, one black rat $(R$. rattus) captured in a house, was found to be seropositive for IgG anti-Y. pestis antibodies, as well as one endemic hedgehog (Tenrec ecaudatus), captured in the crops, and three microgales (endemic shrews) captured in the forest above the village. One of these microgales was only found to be carrying an endemic flea (Paractenopsyllus pauliani), that had never before been suspected to be involved in plague transmission.

\subsection{Relic forests of the Highlands: new reservoirs, new vectors, new bacteria; appearance of a sylvatic cycle?}

The Ambositra region was Madagascar's most active plague focus in the 1980's and 1990's [10] and new genetic variants of the plague bacillus appeared there [33]).

Within the zone where these new strains appeared, micro-mammals and fleas were sampled in a mosaic of farmland and forest, characteristic of this area [19]. In a particularly active focus (Ankazomivady, near Ambositra), during one single trapping session, six strains of $Y$. pestis were isolated from the spleens of five black rats and of one endemic hedgehog (Hemicentetes nigriceps): all these mammals were captured in the forest. The large number of strains collected here, indicates that the plague bacillus circulates widely. Furthermore, the strain isolated from the hedgehog proved to belong to one of the new bacillus variants (ribotype $Q$, E. Carniel, personal communication). Several kilometers away, in the same environment, one year later, no plague bacillus was isolated by bacteriological analyses. However, the presence of anti F1 antibodies of $Y$. pestis was established in seven $R$. rattus and in one other endemic hedgehog, Setifer 
setosus. We did not find either one of the usual plague vectors (X. cheopis and S. fonquerniei) on the micromammals captured in the forest. Yet four species of endemic fleas, previously not suspected to be possible vectors, were found, in particular on the eight plague-infected animals. Deforestation, here as in the rest of the country, favors the penetration of $R$. rattus into the forest [30]. Therefore, as a result of contact with endemic species (rodents and insectivores), the flea fauna on $R$. rattus is here completely different than that in an agricultural environment ${ }^{2}$. The appearance of these new $Y$. pestis strains may be linked to the existence of endemic reservoirs, but more probably to the implication of new flea vectors in the epidemiological cycle.

The new Y. pestis variants (ribotypes $\mathrm{Q}$, $\mathrm{R}$ and $\mathrm{T}$ ), isolated from humans, came from wooded areas. This forest plague is likely to have originated in rural foci and to be transported by the black rat. Nevertheless, in the light of the emergence of new bacillus variants, the high level of circulation in certain forests and the occurrence of human epidemics nearby, the hypothesis of an independent forest plague, dissociated from rural foci, is currently being reexamined [19].

\section{FACTORS INVOLVED IN REEMERGENCE}

\section{1. "Forgotten" ancient foci and discontinued surveillance}

Since the 1920's, plague had disappeared from the coastal regions of Madagascar and was limited only to the High Plateau at the center and north (Doany) of the island, above $800 \mathrm{~m}$ of altitude [6]. Therefore surveillance of reservoirs and vectors was discontinued below this altitude. This was the

\footnotetext{
2 Duchemin J.B., Biogéographie des puces de Madagascar, Ph.D. thesis, Paris XII, Val de MarneCréteil University, 2003, 253 p.
}

prevailing context when the focus of the Mahajanga harbor appeared in 1991.

In India, no human cases of plague had occurred between 1966 and 1994; then in 1994 a human plague epidemic reappeared. At the beginning of the 1980's, vector populations and reservoirs were still being monitored in some urban areas (see for example [53] in Bombay), but this surveillance had been partially suspended afterwards [61].

The most recent reemerging focus of human plague was in Oran, Algeria, in July 2003 [63]. Algeria had been plague-free since the 1950's and no surveillance had been instored since then.

The suspension of surveillance and therefore of any warning and preventive system explains how human cases could reappear so suddenly, while this does not necessarily mean that the foci reemerged. Plague bacteria could very well have continued to circulate at low levels within rodent populations in the areas concerned before affecting human populations on the occasion of a habitat change, the appearance of new bacterial variants, new vectors and/or the introduction of a commensal rodent sensitive to plague. Since surveillance is costly, it is always difficult to convince countries to maintain the surveillance of a rare or almost eradicated disease, especially when resources are already very limited.

Furthermore, most countries affected by the third pandemic have concentrated their surveillance on rats and fleas in harbors, since they agree with the widely accepted (and verified!) hypothesis that the plague bacillus arrived by marine routes. The possible diffusion and persistence of plague within these countries has long been regarded as a secondary problem, unless as in Madagascar, epidemics happened to break out on a regular basis in the center of the country. The existence of wild secondary foci had rarely been imagined and even less frequently investigated; this is why current knowledge is poor regarding the circulation of enzootic plague in many countries. 
In China, the number of human cases is in general consistently low although vast areas are affected by plague $[58,62]$. This is the result of a very active surveillance policy of foci close to inhabited zones, requiring a large number of workers devoted to the task. In this country, new cases of human plague are often observed in areas that had not been listed as human plague foci and had thus not been intensively monitored.

In the former USSR, countries such as Kazakhstan disposed of important human and financial means to monitor the entire territory in search of indications for active plague foci and to control the wild rodents and fleas in these foci [57]. The breakup of the USSR massively reduced the means available for endemic plague surveillance and in the near future we are likely to witness the reemergence of human plague in these areas. Nevertheless, the recent analysis of long-time series in Kazakhstan [14] has resulted in predictive models showing the major importance of reservoir abundance in these foci and this parameter can be estimated in a very simple way and at a low cost, by monitoring the occupancy rate of gerbil burrows.

\subsection{Socio-economic aspects}

The importance of these socio-economics factors is clearly illustrated by the current situation in the United States, where natural plague foci in rodents cover practically the entire western third of the country and yet the annual number of human cases is very small.

On a worldwide scale, since the 1950's there have been two periods of rapid increase in human cases [62]: during the first phase from 1963 to 1977, the number of cases remained stable in Africa and in America, with the increase being due only to the situation in Asia; on the contrary during the second phase between 1983 and 2001, the increase was mainly observed on the African continent. A finer analysis reveals that the first period concerned mainly Vietnam and coincided with the war in this country. In the 1980's, the affected zones in Africa were in the Great Lakes area, Mozambique and Madagascar, at a time where all these zones were experiencing political unrest or civil wars.

In Madagascar, the number of human cases increased at the end of the 1980's [9]. This coincided with major political unrest in the country and a disastrous economic situation, resulting in an impoverishment of the population, a disorganization of public services in general and health services in particular (suspension of preventive insect control campaigns, reduction of the means of surveillance).

In Mozambique, the situation is more extreme, with plague foci located along the border with Malawi, a country with endemic plague. The civil war brought about great population movements and totally ruined the country's economy: settlement of refugee camps, high density of population with unsuitable hygienic conditions, malnutrition, lack of medical surveillance, ...

During the first two pandemics, plague was considered as a fair disease that affected all social classes, but this is no longer true. In the past, everyone lived in equally bad hygienic conditions, but today the distribution of human cases within a focus is far from random. In the Malagasy capital, Antananarivo, for example, the most affected districts are clearly the poorer and most insalubrious parts of town in the lowlands. This observation also holds true for the focus of the Mahajanga harbor: the affected zones are at the harbor and in peripheral districts where roads, water supply, and cleaning are insufficient, while the center of town (administrative and old residential district) is unaffected $[4,35]$. In villages in the middle-west of Madagascar, our observations led to the same conclusions: the zones the most affected are the poorest huts at the periphery of the villages, inhabited by the most recent arrivals [35]. The richest homes have several rooms and 
sometimes even several levels with welldefined and exclusive uses: food stocking in some, sleeping quarters in others; roofs are usually made of hard material (tiles, sheet metal) that provide little shelter for rodents. In addition, these roofs are often separated from the rooms by false ceilings. Usually the poorest huts have just one room where people sleep next to food supplies. They lie on the floor on mats, right next to the holes of commensal rodents. Furthermore, the thatched roofs on these huts provide shelter where black rats can build their nests. The probability of contact between humans, rats and fleas is therefore far greater in this type of precarious human habitat.

\subsection{Deforestation and its consequences}

As shown above for Madagascar, deforestation has two consequences: first the possibility of contact with forest cycles that had previously been isolated from humans; secondly the creation of new landscapes (steppes, agricultural lands), that favor the development of rodents that are plague reservoirs. In addition, new farmlands are generally cultivated by migrants living in poor conditions - at least initially - which is an aggravating factor.

The literature mentions a few cases of plague circulating in forest habitats. The exceptions deal with temperate forest environments (California, [11, 13]). Most tropical endemic plague zones do not seem to present any forest foci (see for example: Zaire [43, 44], Vietnam [56]). Yet there is obviously a bias: historically, and this is understandable in emergency situations, most studies of plague reservoirs have been concentrated to the zones where human epidemics were occurring, and although large samples of local wildlife were usually analyzed, they were practically all captured in the villages and their immediate surroundings. We wish to underline the great importance of collaborations such as those established in Madagascar between conservation and zoology structures such as WWF and the Field Museum of Chicago on the one hand, and biomedical research organizations such as IRD and Institut Pasteur on the other hand; with the help of multidisciplinary teams it becomes possible to sample forest environments outside of sanitary contingencies.

However, the opening up of new territories to known plague reservoirs is of major importance in the spreading of natural foci and the reemergence of human cases. Replacement of forests by rocky or sandy arid zones favors Gerbillinae (gerbils, meriones, Tatera, ...) and Dipodidae (jerboas), and the steppes are favorable to Sciuridae (marmots, Spermophilus, prairie dogs, ...). When cleared land is cultivated, this provides abundant food resources for rodents and opportunities for outbreaks. The larger number of rodents as compared to forest habitats and the stronger human presence will lead to more frequent contact between humans and rodents, thus increasing the risk of transmission. Introducing sensitive commensal rodents such as the black rat is another aggravating factor.

In China, many regions have undergone large deforestations in response to the demographic pressure, in order to create new croplands (see review in [28]). In the Ganzu province, this deforestation has caused profound landscape modifications and simultaneous changes in the rodent populations $[28,29]$. This has already entailed consequences for one human disease: alveolar echinococcosis, with an increase in the number of human cases [29]. Yet this province is also a plague focus [31] and the rodent species that benefit from an increase in open land (crops or steppes) are also plague reservoirs: the number one plague reservoir in this focus, Spermophilus alaschanicus, does not exist in dense forests, yet it can be encountered in open woodlands and it proliferates in prairies and steppes; two other rodents found carrying plague in this area, Myospalax fontanieri and Tscherkia triton are now dominant species in farmlands [28]. 


\subsection{Appearance of new actors in the cycle}

\subsubsection{New reservoirs?}

This is likely the case with the Asian musk shrew Suncus murinus in the focus of the Mahajanga harbor (see above). This shrew, originating from Southeast Asia was introduced into Madagascar by humans [37]: first recorded in the middle of the 19th century, but probably present earlier. It is present in all environments but always far less abundant than the black rat. It often lives inside houses. It has been found carrying the $Y$. pestis bacteria in Cambodia, China and Vietnam [40]. It regularly carries the flea vector of plague, $X$. cheopis, and has often been suspected to play a role in disease transmission in Asia [40, 47, 54, 56]. However, its role in human foci has always been considered unimportant due to its low abundance, as compared with the rodents captured in these foci. The example of Mahajanga shows that it is now necessary to monitor these shrew populations that are abundant throughout Southeast Asia, the Pacific and the Indian Ocean.

The anti- $Y$. pestis serologies performed on the micro-mammals of Malagasy forests show a clearly higher prevalence in tenrecs (endemic hedgehogs) than in other small mammals (microgales, rats and endemic rodents) [19]. Since one strain was isolated from an endemic Malagasy hedgehog and since tenrecs carry many fleas, this makes these animals likely candidates for plague reservoirs and/or vectors. Tenrecs hibernate as do marmots and terrestrial squirrels, which are classical hosts for plague. The phenomenon of hibernation, quite common among reservoir mammals in natural foci, poses the hypothesis of a possible metabolic or immunological cause in the persistence of the condition of the reservoir. However, it also highlights the importance of fleas, whose population dynamics are linked to this hibernation and/or to climatic factors that trigger hibernation: for example in
California, juvenile squirrels (Spermophilus beecheyi) come out when fleas (Oropsylla montana) are most abundant and this sets off epizootics, a phenomenon that is not observed at lower altitudes where the higher temperature limits the population dynamics of fleas [38]. This underlines the importance of flea-host dynamics studies in a plague context and may highlight behavioral factors in mammals for epizootics in other foci.

\subsubsection{New vectors?}

The fleas that were collected on small mammals in the Ankazomivady/Ambalamanakana forest focus belong to species that had previously not been suspected to be involved in plague transmission in Madagascar. The endemic flea, S. fonquerniei traditionally implicated in rural cycles of plague is rarely captured in the humid and cold forests at medium altitude ${ }^{2}$. It is replaced by another flea belonging to the same genus, $S$. estradei, which in turn is rarely captured in open environments. This flea's competence as a vector, or its genetic biological capacity, independent of environmental factors, to transmit the plague bacillus has not been studied in the laboratory, yet its massive presence on an endemic hedgehog and on black rats captured in the forest points towards an important role in the cycle of plague transmission in a forest environment. Similarly, the flea Dinopsyllus brachypecten is characterized by a comparable spectrum of hosts, while other species of this genus are involved in plague transmission in Africa. A great number of new species of fleas have recently been described in medium-altitude forests in Madagascar [17, 18] and they can be added to the list of potential vectors, particularly those fleas with a wide host spectrum and the ability to transmit the bacillus from one host (hedgehog?) to another (the black rat). In a different context, in the USA, when plague emerged among prairie dog colonies, the presence of fleas infested with $Y$. pestis and belonging to species that are 
usually parasites of other rodent species was noted in many burrows (see review in [12]).

It is interesting to note that in Madagascar, X. cheopis is totally absent inside the forest, but some specimens have been captured in logger's homes along the forest edges. Fleas that are new in the transmission cycle all have a strong preference for forest biotopes, which is mainly attributable to certain characteristics of the larva's physiology rather than to the host spectrum available in these environments. As a consequence, deforestation would tend to cause their disappearance instead of favoring their propagation. We must note here the importance of plague and of wide-spectrum flea vectors in the spreading of the murine enzootic to the endemic Malagasy wildlife. We previously saw that circulation among tenrecs and microgales is high. Endemic Malagasy rodents are very sensitive to plague ([6]: historical experimental infections, observation of epizootics among endemic rodents, absence of endemic rodents carrying anti-plague antibodies) and circulation of plague in these forest environments has a deep impact on this wildlife, in association with the impact of deforestation [19].

In California, the first mention made of a forest focus in a temperate zone [11] revealed, among the fleas collected, several already known species of vectors without any evidence that new species were noticeably involved. Let us mention here the particular case of East African foci where fleas from the black rat (X. cheopis, X. brasiliensis) are found in abundance on local rodents such as Mastomys natalensis, Arvicanthis abyssinicus or Tatera robusta [45]. Yet the more common situation, similarly to what we have seen in Madagascar, is noted in the focus of Serra Dos Orgaos in Brazil [15], where sylvatic fleas are more frequently found on commensal rodents, than commensal fleas on wild rodents. This pattern shows that contact is easy between a commensal rodent reservoir and new fleas in transition zones between natural and manmade environments.

These potentially new vectors may have an impact on $Y$. pestis strains as we will see below.

\subsubsection{New bacteria?}

$Y$. pestis is a highly clonal species that emerged recently (1 500 to 20000 years ago) from Y. pseudotuberculosis [1]. Despite the low genetic and phenotypic polymorphism of $Y$. pestis, three biovars can be distinguished based on their ability to ferment glycerol and to reduce nitrates [16]. The strain that spread from Hong-Kong, causing the third pandemic was of biovar Orientalis. Isolates of this biovar are now found in most endemic countries (USA, South America, Vietnam, Madagascar, South Africa).

- Emergence of new ribotypes

Analysis of the restriction fragment length polymorphism of the regions carrying the rRNA genes (i.e. ribotyping) made the subdivision of this species possible and showed that the strain which caused the third pandemic was of ribotype B [32]. Plague was introduced for the first time in Madagascar in 1898, during the third pandemic, by a ship coming from India. An extensive analysis of $Y$. pestis strains isolated between 1939 and 1996 from different regions of the island showed that before 1982, all strains were, as expected, of biovar Orientalis and ribotype B [33]. In 1982, 1983 and 1994, Y. pestis strains with new ribotypes, designated $\mathrm{R}, \mathrm{Q}$ and $\mathrm{T}$, respectively, were isolated from the most active plague focus (Ambositra-Ambohimahasoa) on the high plateau. A follow-up of these new variants indicated that strains of ribotype $\mathrm{Q}$ and $\mathrm{R}$ are now well established in their ecosystem and have a tendency to spread to new geographical areas and substitute to the original classical strain. The new variants could also be distinguished from the ribotype B parental strain by specific genomic and/or plasmid profiles. 
The same phenomenon was observed in India. This country was struck by plague in 1898 and over 12 million Indians died of this disease between 1898 and 1928 [61]. While a $Y$. pestis strain isolated in Bombay at the beginning of the last century had the classical ribotype $\mathrm{B}$, the three $Y$. pestis strains isolated during the 1994 outbreak in Surat from the lungs of patients who died of pneumonic plague had a new ribotype, designated $S$ [32, 50]. Since strains of ribotype $S$ were subsequently isolated from rodents, it shows that a latent plague focus colonized by this strain existed before the human outbreak.

\section{- Genome plasticity}

The use of pulsed-field gel electrophoresis (PFGE), revealed that the genome of $Y$. pestis is subject to numerous and spontaneous genomic rearrangements, which occur at high frequencies [32]. This genome fluidity may facilitate the continuous emergence of new $Y$. pestis clones, some of them having potentially acquired an optimal capacity to adapt to a new environment.

\section{- Horizontal gene acquisition}

$Y$. pestis also has the ability to acquire foreign DNA by horizontal transfer in its natural environment. In 1995, two strains isolated from patients in different regions of Madagascar were found to have acquired two genetically unrelated antibiotic resistant plasmids [26, 34]. These plasmids could be readily transmissible to other $Y$. pestis strains under laboratory conditions. It was subsequently demonstrated that this plasmid acquisition occurs at high frequencies in the flea gut [36]. Thus, transit in its arthropod vector exposes $Y$. pestis to favorable conditions for efficient genetic exchange with the microbial flora of the flea gut. The multitude of flea and reservoir species observed in the Madagascar highland forests widens the scope of pressures of acquisition or selection for new genetic material in this bacteria, and can or could have favored the emergence of new variants in the Ambositra area.

- Co-adaptation between $Y$. pestis and its flea vectors?

The possible genetic evolution of $Y$. pestis in relation to its host (vector or reservoir) is not necessarily valid in the opposite direction: there does not seem to be any form of co-adaptation between $Y$. pestis and fleas: (i) within the same genus of fleas, some species are efficient in bacteria transmission whereas others are not; (ii) species belonging to distant genera present the same efficiency of transmission. Furthermore, selective pressures leading to speciation in fleas seem to operate mainly on the larval stages (see the above section on preference for forest biotopes) than on potentially infected adult stages. Most of all, the plague bacillus may often have a deleterious effect on fleas since they can starve when the proventriculus of their oesophagus is blocked, so survival and reproductive output are diminished. The mammal host may also have reduced survival, forcing the flea to spend extra energy in search of a new host. Therefore, although transmission of plague is very effective by blocking the proventriculus, fleas do not seem to obtain any benefit there and so the concept of coadaptation can be rejected here.

These examples demonstrate that in less than one century (which, from an evolutionary point of view represents a very short period of time), the original $Y$. pestis strain that spread over the world during the third pandemic had undergone rearrangements, leading to the local emergence of new variants which may have possibly gained selective advantages. These rearrangements may confer selective advantages to the organism, enhancing its ability to survive, to be transmitted to new hosts, and to colonize its environment. However, the direct role of these rearrangements in conferring new and advantageous properties to the host bacterium remains to be demonstrated. 


\subsection{Climate change}

\subsubsection{Global warming}

When drought is associated with deforestation and over-exploitation of the soil, this leads to the extension of steppes and desertic zones. This in turn favors the expansion of known reservoirs such as Gerbillinae (gerbils, meriones, etc.) in these arid zones. The extension can take place at the periphery of already known foci, and sometimes favorable new zones for reservoirs and vectors can be created at a distance of the focus; in our modern society dispersal of animals is facilitated by the growing intensity and speed of human movements. In West Africa for example, as a consequence of the drought observed since 1970, the distribution area of gerbils increased southwards by around $200 \mathrm{~km}[20]^{3}$. The same increase has been observed for the tick, Alectorobius sonrai, vector of borreliosis and human cases have appeared in this area [59]. But global warming does not necessarily have the same consequences for plague: even though it is clearly a positive factor for the expansion of plague reservoirs, it may be the opposite for plague vectors. Numerous authors consider that high temperatures reduce flea survival and also affect the ability of fleas to transmit plague, by reducing the blocking rates [23].

\subsubsection{Climatic oscillations}

A correlation between cycles of abundance of small mammals and the ENSO (El Nino Southern Oscillations) phenomenon has been demonstrated in Chile [39] and New Mexico [5]. Conversely, while Parmenter et al. [46] demonstrated the local importance of rainfall, they found no strong correlation between ENSO and the occur-

\footnotetext{
${ }^{3}$ Ba K., Systématique, écologie et dynamique de populations de petits rongeurs potentiellement reservoirs ou hôtes du virus au Sénégal, Mémoire de Diplôme EPHE, Université de Montpellier 2, 2002, $126 \mathrm{p}$.
}

rence of human cases of plague in the USA. In the southwestern USA, a relationship between climate and frequency of human plague cases has recently been demonstrated [23]. The most important climatic parameters are the maximum daily summer temperature and the time-lagged (1-2 years) rainfall in late winter. These parameters are obviously associated with flea abundance for the former and with rodent abundance for the latter.

The reemergence of human cases of plague in Botswana in 1989, after 38 years of silence, occurred after a very rich harvest caused an increase in rodent populations and the invasion of villages by wild rodents [58]. The most recent plague focus in Oran (Algeria) also seems to have appeared after exceptionally favorable rainfalls for crops and a rich harvest.

\subsection{Increases in human movement}

In Madagascar the introduction of plague into the High Plateau is clearly related to the construction of the railroad between the main port Tamatave (entry gateway of plague into Madagascar in 1898) and the capital city of Antananarivo, located at the center of the island. The mortality of black rats but also of endemic rodents, followed by human cases had been mentioned along this line before plague reached the capital in 1921 [6].

On a worldwide scale, the capital importance represented by the evolution of human movements has already been clearly demonstrated by the speed and mode of diffusion of the third plague pandemic. Starting in China in 1894, this pandemic spread worldwide within less than five years. Its arrival in the harbors of all continents is well documented and the major role of sea traffic by steam navigation is evident in the speed of its diffusion [47].

Concerning rodent plague, transportation of fleas infested by $Y$. pestis over long distances by predators (coyotes, raptors) has also been considered as an explanation 
for the reemergence of plague in distant prairie dog colonies in the USA [12].

\subsection{Natural disasters}

In India, one year before human plague reemerged, a major earthquake occurred in Latur, a region near Beed where the first cases of bubonic plague had been reported [58]. In Algeria also, an earthquake had occurred not far from Oran before the plague epidemic. It is indeed difficult to determine whether these are coincidences or whether a causal relationship exists. In any case, earthquakes can damage or destroy underground tunnel networks and burrows of rodent reservoirs, thus forcing them to leave, to disperse and to come into contact with and contaminate sensitive small mammals and humans. Floods may act in a similar way, pushing masses of infested rodents out of their flooded burrows: they are then liable to seek shelter in inhabited areas. This parameter has been examined regarding the epidemic in India [58].

\section{CONCLUSIONS}

Many factors that can favor the reemergence of plague are also involved in other diseases: economical and political crises [25], climate change [27], the increase of human movements [60], are frequently invoked in the reemergence of other diseases such as malaria [27], arbovirus diseases [42, 55], etc.

"Emergence of infectious diseases is complex": this is the first basic concept in disease emergence, according to Wilson [60]. And this is fully verified with plague. If we carefully study the history of each reemerging focus described above, it appears that in all cases more than one factor was at the origin of reemergence, operating in conjunction with at least another factor.

Consider the case of the Mahajanga harbor: an ancient focus was forgotten (abandon of the surveillance of potential reservoirs and vectors), so commercial exchanges with the agricultural plague focus in the north of the island favored the re-introduction of plague in town. But, persistence of this focus during the three years of apparent silence (no human cases from 1992 to 1994) following its reemergence and the four successive years of annual epidemics (19951999), is clearly due to a new reservoir, the shrew Suncus murinus. The geographic distribution of human cases within the town, and the disappearance of human plague in 1999 due to important sanitary improvement operations following a cholera epidemic (a new disease for Madagascar, [22] and apparently more alarming than plague) shows the importance of insalubrity in the emergence of human plague.

In the mosaic landscape of forests and crops at the center of Madagascar, both deforestation, which increases the surface of favorable zones for the reservoir (black rats), and the appearance of new bacterial variants are simultaneously important. They could be related to new contacts with previously isolated forest foci: indeed, the new reservoirs (endemic hedgehogs and shrews) and new flea vectors may have appeared at the forest edges.

In India the abandon of surveillance occurred simultaneously with natural disasters (floods, earthquakes) and the appearance of new $Y$. pestis variants. The second focus (Surat) illustrates the importance of human movements, which were here multiplied by panic movements, in the emergence of secondary foci, particularly in cases of pneumonic plague.

On a worldwide scale, it is now clear that ancient foci extinguished for decades, must be carefully recorded and monitored, including those that simply seemed affected by the introduction of plague-carrying rats by the sea route, since a permanent low-level installation among wild populations can occur secondarily. A major key-word in plague reemergence, as well as for other reemerging diseases is "instability" [24]. Any change: climatic, ecological (deforestation, urbanization, ...), natural disasters 
(floods, earthquakes, ...), deterioration of living conditions (economic crises, civil wars) should be taken as warning signals and a surveillance program of reservoirs and vectors should be launched. The recent analysis and modeling of long-time series in two plague foci $[14,23]$ has demonstrated that it is possible to focus the surveillance on a few precise parameters (climatic or biological): since surveillance is costly, the determination of such indicators, which are easy to collect, is of major importance in other plague foci.

\section{REFERENCES}

[1] Achtman M., Zurth K., Morelli C., Torrea G., Guiyoule A., Carniel E., Yersinia pestis, the cause of plague, is a recently emerged clone of Yersinia pseudotuberculosis, Proc. Natl. Acad. Sci. USA 96 (1999) 14043-14048.

[2] Barreto A., Aragon M., Epstein P.R., Bubonic plague outbreak in Mozambique, 1994, Lancet 345 (1995) 983-984.

[3] Boisier P., Rasolomaharo M., Ranaivoson G., Rasoamanana B., Rakoto L., Andrianirina Z., Andriamahefazafy B., Chanteau S., Urban epidemic of bubonic plague in Mahajanga, Madagascar: epidemiological aspects, Trop. Med. Int. Health 2 (1997) 422-427.

[4] Boisier P., Rahalison L., Rasolomaharo M., Ratsitorahina M., Mahafaly M., Razafimahefa M., Duplantier J.M., Ratsifasoamanana L., Chanteau S., Epidemiologic features of four successives outbreaks of bubonic plague in Mahajanga (Madagascar), Emerg. Infect. Dis. 8 (2002) 311-316.

[5] Brown J.H., Valone T.J., Curtin C.G., Reorganization of an arid ecosystem in response to recent climatic change, Proc. Natl. Acad. Sci. USA 94 (1997) 9729-9733.

[6] Brygoo E.R., Épidémiologie de la peste à Madagascar, Arch. Inst. Pasteur Madagascar 35 (1966) 9-147.

[7] Brygoo E.R., Human diseases and their relationship to the environment, in: Battistini R., Richard-Vindard G. (Eds.), Biogeography and Ecology of Madagascar, Junk Publishers, The Hague, 1972, 765 p.

[8] Center for Disease Control and Prevention, Imported plague - New York City, 2002, Morb. Mortal. Wkly Rep. 52 (2003) 725-728.
[9] Chanteau S., Ratsifasoamanana L., Rasoamanana B., Rahalison L., Randrianbelosoa J., Roux J., Rabeson D., Plague, a reemerging disease in Madagascar, Emerg. Infect. Dis. 4 (1998) 101-104.

[10] Chanteau S., Ratsitorahina M., Rahalison L., Rasoamanana B., Chan F., Boisier P., Rabeson D., Roux J., Current epidemiology of human plague in Madagascar, Microbes Infect. 2 (2000) 25-31.

[11] Clover J.R., Hofstra T.D., Kuluris B.G., Schroeder M.T., Nelson B.C., Barnes A.M., Botzler R.G., Serologic evidence of Yersinia pestis infection in small mammals and bears from a temperate rainforest of north coastal California, J. Wildl. Dis. 25 (1989) 52-60.

[12] Cully J.F., Williams E.S., Interspecific comparisons of sylvatic plague in prairie dogs, J. Mammal. 82 (2001) 894-905.

[13] Davis R.M., Smith R.T., Madon M.B., SitkoCleugh E., Flea, rodent and plague ecology at Chuchupate Campground, Ventura County, California, J. Vector Ecol. 27 (2002) 107-127.

[14] Davis S., Begon M., De Bruyn L., Ageyev V.S., Klassovskiy N.L., Pole S.B., Viljugrein H., Stenseth N.C., Leirs H., Predictive thresholds for plague in Kazakhstan, Science 304 (2004) 736-738.

[15] De Carvalho R.W., Serra-Freire N.M., Linardi P.M., De Almeida A.B., Da Costa J.N., Small rodents fleas from the bubonic plague focus located in the Serra dos Órgãos Mountain Range, State of Rio de Janeiro, Brazil, Mem. Inst. Oswaldo Cruz 96 (2001) 603609.

[16] Devignat R., Varieties of Pasteurella pestis; new hypothesis, Bull. World Health Organ. 4 (1951) 247-263 (in French).

[17] Duchemin J.B., Two new fleas (Siphonaptera: Ceratophyllidae: Leptopsyllinae) of Madagascar: Tsaractenus rodhaini $\mathrm{n}$. $\mathrm{sp}$. and Paractenopsyllus (Consobrinopsyllus n. subgen.) goodmani n. sp., Parasite 10 (2003) 351358 .

[18] Duchemin J.B., Leptopsyllines from Madagascar (Insecta: Siphonaptera: Ceratophyllidae): description of five new species of Paractenopsyllus Wagner, 1938, Parasite 11 (2004) 59-70.

[19] Duchemin J.B., Duplantier J.M., Goodman S.M., Ratovonjato J., Rahalison L., Chanteau S., La peste à Madagascar : faune endémique et foyers sylvatiques, in: Signoli M. et al (Eds.), Proceedings of the Conference: $\mathrm{La}$ peste : entre épidémies et sociétés, Marseille 23-26 juillet 2001, Erga Edizioni Publishers, Firenze. 
[20] Duplantier J.M., Granjon L., Ba K., Découverte de trois espèces de rongeurs nouvelles pour le Sénégal : un indicateur supplémentaire de la désertification dans le nord du pays, Mammalia 55 (1991) 313-315.

[21] Duplantier J.M., Duchemin J.B., Ratsitorahina M., Rahalison L., Chanteau S., Emergence of plague in the Ikongo district of Madagascar, 1998. 2. Reservoirs and fleas involved, Bull. Soc. Pathol. Exot. 94 (2001) 119-122 (in French).

[22] Duval P., Champetier de Ribes G., Ranjalahy J., Quilici M.L., Fournier J.M., Cholera in Madagascar, Lancet 353 (1999) 2068.

[23] Enscore R.E., Biggerstaff B.J., Brown T.L., Fulgham R.E., Reynolds P.J., Engelthaler D.M., Levy C.E., Parmenter R.R., Montenieri J.A., Cheek J.E., Grinnel R.K., Ettestad P.J., Gage K.L., Modeling relationship between climate and the frequency of human plague cases in the Southwestern United States, 1960-1997, Am. J. Trop. Med. Hyg. 66 (2002) 186-196.

[24] Epstein P.R., Emerging diseases and ecosystem instability: new threats to public health, Am. J. Public Health 85 (1995) 168-172.

[25] Farmer P., Social inequalities and emerging infectious diseases, Emerg. Infect. Dis. 2 (1996) 259-269.

[26] Galimand M., Guiyoule A., Gerbaud G., Rasoamanana B., Chanteau S., Carniel E., Courvalin P., Multidrug resistance in Yersinia pestis mediated by a transferable plasmid, $\mathrm{N}$. Engl. J. Med. 337 (1997) 677-680.

[27] Ghiteko A.K., Lindsay S.W., Confalonieri U.E., Patz J., Climate change and vectorborne diseases: a regional analysis, Bull. World Health Organ. 78 (2000) 1136-1147.

[28] Giraudoux P., Quere J.P., Delattre P., Bao G., Wang X., Shi D., Vuitton D., Craig P.S., Distribution of small mammals along a deforestation gradient in southern Gansu, central China, Acta Theriol. 43 (1998) 349-362.

[29] Giraudoux P., Delattre P., Takahashi K., Raoul F., Quere J.P., Craig P., Vuitton D., Transmission ecology of Echinococcus multilocularis in wildlife: what can be learned from comparative studies and multiscales approaches?, in: Craig P., Pawlowski Z. (Eds.), Cestodes Zoonoses: Echinococcosis and Cysticercosis, IOS Press, 2002, pp. 251-266.

[30] Goodman S.M., Rattus on Madagascar and the dilemna of protecting the endemic rodent fauna, Conserv. Biol. 9 (1995) 450-453.

[31] Gratz N.G., Rodent reservoirs and flea vectors of natural plague foci, in: Dennis D.T., Gage
K.L., Gratz N.G., Poland J.D., Thikhomirov E. (Eds.), Plague manual: epidemiology, distribution, surveillance and control, Chapter 4, Pub. No. WHO/CDS/CSR/EDC/99.2, World Health Organization, Geneva, 1999, pp. 63-96.

[32] Guiyoule A., Grimont F., Iteman I., Grimont P.A.D., Lefevre M., Carniel E., Plague pandemics investigated by ribotyping of Yersinia pestis strains, J. Clin. Microbiol. 32 (1994) 634-641.

[33] Guiyoule A., Rasoamanana B., Buchreiser C., Michel P., Chanteau S., Carniel E., Recent emergence of new variants of Yersinia pestis in Madagascar, J. Clin. Microbiol. 35 (1997) 2826-2833.

[34] Guiyoule A., Gerbaud G., Buchreiser C., Galimand M., Rahalison L., Chanteau S., Courvalin P., Carniel E., Transferable Plasmid-mediated resistance to streptomycin in a clinical isolate of Yersinia pestis, Emerg. Infect. Dis. 7 (2001) 43-48.

[35] Handschumacher P., Duplantier J.M., Chanteau $\mathrm{S}$., La résurgence de la peste à Madagascar : une maladie centenaire à l'épreuve de l'histoire et de l'écologie, Espace Popul. Soc. 2 (2000) 195-208.

[36] Hinnebusch B.J., Rosso M.L., Schwan T.G., Carniel E., High-frequency conjugative transfer of antibiotic resistance genes to Yersinia pestis in the flea midgut, Mol. Microbiol. 46 (2002) 349-354.

[37] Hutterer R., Tranier M., The immigration of the Asian house shrew (Suncus murinus) into Africa and Madagascar, in: Peters G., Hutterer R. (Eds.), Vertebrates in the Tropics, Museum Alexander Koenig, Bonn, 1990, pp. 309-319.

[38] Lang J.D., Factors affecting the seasonal abundance of ground squirrel and wood rat fleas (Siphonaptera) in San Diego County, California, J. Med. Entomol. 33 (1996) 790804.

[39] Lima M., Marquet P.A., Jaksic F.M., El Nino events, precipitation patterns, and rodent outbreaks are statistically associated in semi-arid Chile, Ecography 22 (1999) 213-218.

[40] Marshall J.D., Quy D.V., Gibson F.L., Dung T.C., Cavanaugh D.C., Ecology of plague in Vietnam. I. Role of Suncus murinus, Proc. Soc. Exp. Biol. Med. 124 (1967) 1083-1086.

[41] Migliani R., Ratsitorahina M., Rahalison L., Rakotoarivony I., Duchemin J.B., Duplantier J.M., Rakotonomenjanahary J., Chanteau S., Emergence of plague in the Ikongo district in Madagascar in 1998. 1. Epidemiological aspects in the human population, Bull. Soc. Pathol. Exot. 94 (2001) 115-118 (in French). 
[42] Mills J.M., Childs J.E., Ecologic studies of rodent reservoirs: their relevance for human health, Emerg. Infect. Dis. 4 (1998) 529-536.

[43] Misonne X., The rodents of the areas of the Congolese plaguel, Ann. Soc. Belg. Med. Trop. 39 (1959) 436-494 (in French).

[44] Misonne X., 40 years of the anti-plague campaign in the Congo, Ann. Soc. Belg. Med. Trop. 49 (1969) 1-16 (in French).

[45] Msangi A.S., The surveillance of rodent populations in East Africa in relation to plague endemicity, Dar Salam University Science Journal 1 (1975) 8-20.

[46] Parmenter R.R., Yadav E.P., Parmenter C.A., Ettestad P., Gage K.L., Incidence of plague associated with increased winter-spring precipitation in new Mexico, Am. J. Trop. Med. Hyg. 61 (1999) 814-821.

[47] Pollitzer R., Plague, WHO Monograph series No. 22, Genève, 1954.

[48] Pulliam H.R., Sources, sinks and habitat selection, Am. Nat. 132 (1988) 652-661.

[49] Rahalison L., Ranjalahy M., Duplantier J.M., Duchemin J.B., Ravelosaona J., Ratsifasoamanana L., Chanteau S., Susceptibility to plague of the rodents in Antananarivo, Madagascar, Adv. Exp. Med. Biol. 529 (2003) 439-442.

[50] Ramalingaswami V., Plague in India, Nat. Med. 1 (1995) 1237-1239.

[51] Rasolomaharo M., Rasoamanana B., Andrianirina Z., Buchy P., Rakotoarimanana N., Chanteau S., Plague in Majunga, Madagascar, Lancet 346 (1995) 1234

[52] Ratsitorahina M., Migliani R., Ratsifasoamanana L., Ratsimba M., Chan Tho Hine F., Rahalison L., Chanteau S., Recrudescence and geographic extension of the plague in Madagascar from 1980 to 1999, Arch. Inst. Pasteur Madagascar 67 (2001) 14-18 (in French).
[53] Renapurkar D.M., Observations on commensal rats and their status to plague in Bombay, J. Hyg. Epidemiol. Microbiol. Immunol. 32 (1988) 407-413.

[54] Renapurkar D.M., Suncus murinus. Observations on ecology, distribution, status to plague in Bombay, J. Hyg. Epidemiol. Microbiol. Immunol. 33 (1989) 45-49.

[55] Saluzzo J.P., Dodet B., Factors in the emergence of arboviruses diseases, Elsevier/Fondation Mérieux, Paris, 1997.

[56] Suntsov V.V., Huong L.T., Suntsova N.I., Gratz N.G., Plague foci in Viet Nam: zoological and parasitological aspects, Bull. World Health Organ. 74 (1997) 117-123.

[57] Temporary Handbook on Epizootic Surveillance of the Central Asian desert plague focus, Alma-Ata, 1972, pp. 3-87 (in Russian).

[58] Tikhomirov E., Epidemiology and distribution of plague, in: Dennis D.T., Gage K.L., Gratz N.G., Poland J.D., Thikhomirov E. (Eds.), Plague manual: epidemiology, distribution, surveillance and control, Pub. No. WHO/ CDS/CSR/EDC/99.2, World Health Organization, Geneva, 1999, Chapter 1, pp. 11-41.

[59] Trape J.F., Godeluck B., Diatta G., Rogier C., Legros F., Albergel J., Pépin Y., Duplantier J.M., The spread of tick-borne borreliosis in West Africa and its relation to sub-Saharan drought, Am. J. Trop. Med. Hyg. 54 (1996) 289-293.

[60] Wilson M.E., Travel and the emergence of infectious diseases, Emerg. Infect. Dis. 1 (1995) 39-46.

[61] Word Health Organization, WHO consultation on plague (New Delhi, India, 11 to 15 September 1989), WHO report No. WHO/ MIM/PLA/90.1, 1990, 21 p.

[62] Word Health Organization, Human plague in 2000 and 2001, Wkly Epidemiol. Rec. 78 (2003) 130-135.

[63] Word Health Organization, Plague, Algeria, Wkly Epidemiol. Rec. 78 (2003) 253. 